\title{
Endothelial Nitric Oxide Synthase Polymorphisms and Haplotypes in Amerindians
}

\author{
Marcelo R. Luizon, ${ }^{1}$ Tatiane C. Izidoro-Toledo, ${ }^{1}$ Aguinaldo L. Simoes, ${ }^{2}$ and Jose E. Tanus-Santos ${ }^{1}$
}

Interethnic disparities in the distribution of endothelial nitric oxide synthase (eNOS) polymorphisms may affect nitric oxide (NO)-mediated effects of and responses to drugs. While there are differences between black and white subjects there is no information regarding the distribution of eNOS gene alleles and haplotypes in Amerindians. We studied three clinically relevant $e N O S$ polymorphisms $\left(\mathrm{T}^{-786} \mathrm{C}\right.$ in the promoter, a variable number of tandem repeats in intron 4, and the Glu298Asp in exon 7) and eNOS haplotypes in 170 Amerindians from three tribes of the Brazilian Amazon. The results were compared with previous findings for black and white Brazilians. The Asp298, $\mathrm{C}^{-786}$, and 4a alleles were much less common in Amerindians $(5.0 \%, 3.2 \%$, and $4.1 \%$, respectively) than in blacks $(15.1 \%, 19.5 \%$, and $32.0 \%$, respectively) or whites $(32.8 \%, 41.9 \%$, and $17.9 \%$, respectively) $(p<0.001)$. The haplotype including the most common alleles for each polymorphism was much more common in Amerindians (89\%) than in blacks $(45 \%)$ or whites $(41 \%)$. Our findings are consistent with a lower genetic diversity in Amerindians compared with blacks and whites. These striking differences may be of major relevance for case-control association studies focusing on eNOS gene polymorphisms and may explain, at least in part, differences in the responses to cardiovascular drugs.

\section{Introduction}

$\mathbf{N}$ ITRIC OXIDE (NO) PLAYs a major role in vascular homeostasis. Produced in endothelial cells and platelets by endothelial NO synthase (eNOS) (Tanus-Santos et al., 2002), NO mediates vascular dilation, inhibits platelet aggregation, regulates posttranslational protein modification, cell migration and angiogenesis, and apoptosis (Cooke et al., 2007). Indeed, reduced bioavailability of NO has been linked to numerous important cardiovascular pathological processes (Yetik-Anacak and Catravas, 2006; Sandrim et al., 2008b), and there is now evidence of a genetic contribution to the variability in NO formation (Metzger et al., 2005, 2007). Due to the relevance of NO in the regulation of the cardiovascular system, eNOS gene polymorphisms have been associated with cardiovascular diseases (Hingorani, 2001; Casas et al., 2006). A few studies have recently shown that eNOS polymorphisms affect drug responses (Nagassaki et al., 2006, 2008; Souza-Costa et al., 2007). Importantly, three clinically relevant polymorphisms have been widely studied: a single nucleotide polymorphism (SNP) in the promoter region $\left(\mathrm{T}^{-786} \mathrm{C}\right.$, rs 2070744), an SNP in exon 7 (G894T, rs1799983), and the variable number of tandem repeats (VNTR) in intron 4 (Casas et al., 2006). In this regard, Sandrim et al. (2006a, 2006b, 2007, 2008a) and Nejatizadeh et al. (2008) have shown that eNOS haplotypes are associated with hypertensive disorders in black and white subjects and in patients with type 2 diabetes mellitus. However, associations of individual eNOS polymorphisms with hypertension, preeclampsia, stroke, and diabetes remain uncertain (Casas et al., 2006). One possible explanation for contrasting results is that most association studies focus on the contribution of a single polymorphism to a specific clinical condition and may not have the power to detect modest effects. Population stratification resulting from ethnic diversity may also decrease the power of association studies (Cardon and Bell, 2001). These factors often confound and dilute the power of case-control studies that are usually designed to identify genetic risk factors for a disease, especially when ethnic variations in allele frequencies in cases and controls are not matched (Risch, 2000). It follows that information regarding the distribution of eNOS alleles in different ethnic groups may help to improve the design of association studies and also help to explain interethnic differences in drug responses (Nagassaki et al., 2006, 2008; Souza-Costa et al., 2007).

Consistent differences in the distribution of eNOS alleles were reported when African Americans were compared to Caucasian Americans (Tanus-Santos et al., 2001) and when blacks were compared to whites in Brazil (Marroni et al., 2005). The haplotype distributions showed similar interethnic differences in these two populations (Tanus-Santos et al., 2001; Marroni et al., 2005). These interpopulation differences 
may in part explain the ethnic disparities in NO bioavailability, cardiovascular risk, and response to drugs (Stein et al., 1997; Sareli et al., 2001; Kalinowski et al., 2004; Li et al., 2004). While the present-day Brazilian population results from extensive interethnic crosses between individuals from different continents, including Europeans, Africans, and autochthonous Amerindians (Parra et al., 2003; Ferreira et al., 2006), there are no data regarding the frequency of eNOS alleles and haplotypes in Amerindians.

In the present study, we hypothesized that significant differences exist in the distribution of eNOS genotypes and haplotypes when Amerindians are compared with white and black subjects from Brazil. Therefore, we examined the allele distribution of three clinically relevant polymorphisms found in the eNOS gene in three Amerindian tribes from Brazilian Amazon $(n=170)$, which are characterized by low admixture levels (estimated as 2-3\%) with nonindigenous people (Luizon et al., 2008). We then estimated the haplotype frequency, evaluated associations between these alleles, and compared with previous data from black and white Brazilians (Marroni et al., 2005).

\section{Materials and Methods}

\section{Subjects}

The procedures were reviewed and approved by the Institutional Review Board at the Faculty of Medicine of Ribeirao Preto. Blood samples were collected in 1976 for protein and blood group analysis studies (Mestriner et al., 1980; Neel et al., 1980). The buffy coat was removed by aspiration, and after plasma separation packed cells were diluted in 30\% buffered glycerol and kept at $-20^{\circ} \mathrm{C}$. One hundred and seventy individuals without direct kinship (siblings or parents / sibs) were selected from the Tikuna tribe $(n=114)$, located upper Solimões River in the Amazonas State, Brazil (latitude $4^{\circ} 15^{\prime}-4^{\circ} 17^{\prime} \mathrm{S}$, longitude $\left.69^{\circ} 35^{\prime}-69^{\circ} 55^{\prime} \mathrm{W}\right)$; from the Baníwa tribe $(n=26)$, located northwest of Amazonas, along the Colombian border $\left(1^{\circ} 33^{\prime} \mathrm{N}, 68^{\circ} 44^{\prime} \mathrm{W}\right)$; and from the Kanamari tribe $(n=30)$, located southwest of Amazonas, in the Juruá River watershed $\left(6^{\circ} 37^{\prime} \mathrm{S}, 69^{\circ} 32^{\prime} \mathrm{W}\right)$. Only individuals with different surnames were selected from each tribe. These tribes represent four major linguistic groups that cover an extensive area of the Amazon Basin.

\section{Genotyping}

$\mathrm{T}^{-786} \mathrm{C}$ polymorphism in the $5^{\prime}$-flanking region of eNOS. Genotypes for the $\mathrm{T}^{-786} \mathrm{C}$ polymorphism in the $5^{\prime}$-flanking region of $e N O S$ were determined by polymerase chain reaction (PCR) amplification using the primers $5^{\prime}$-TGGAG AGTGCTGGTGTACCCCA-3' (sense) and $5^{\prime}$-GCCTCCACCC CCACCCTGTC- $3^{\prime}$ (antisense) and PCR conditions as previously described (Marroni et al., 2005). The amplified products were digested with $M s p I$ for at least 3 hours, at $37^{\circ} \mathrm{C}$, producing fragments of 140 and $40 \mathrm{bp}$ for the $\mathrm{T}$ allele or 90 , 50 , and $40 \mathrm{bp}$ for the $\mathrm{C}$ allele. Fragments were separated by electrophoresis in $10 \%$ polyacrylamide gels and viewed by silver staining.

Glu298Asp (G894T) polymorphism in exon 7. For detecting the Glu298Asp polymorphisms in exon 7, the primers 5'-AAGGCAGGAGACAGTGGATGGA-3' (sense) and 5'CCCAGTCAATCCCTTTGGTGCTCA-3' (antisense) and PCR conditions as previously described (Tanus-Santos et al., 2001; Marroni et al., 2005; Sandrim et al., 2006b) were used. The resulting $258 \mathrm{bp}$ fragment was digested with the enzyme Ban II for 6 hours, at $37^{\circ} \mathrm{C}$, producing $163 \mathrm{bp}$ and $85 \mathrm{bp}$ fragments ( $G$ allele) or no digestion ( $T$ allele), which were analyzed by gel electrophoresis in $8 \%$ polyacrylamide gels and viewed by silver staining.

VNTR (27 bp-repeat) polymorphism in intron 4 . Genotypes for the polymorphic VNTR in intron 4 were determined by PCR using the primers $5^{\prime}$-AGGCCCTATGGTAGTGCCTT T- $3^{\prime}$ (sense) and $5^{\prime}$-TCTCTTAGTGCTGTGGTCAC-3' (antisense) and PCR conditions as previously described (Marroni et al., 2005; Sandrim et al., 2006a, 2006b). Fragments (420 and/or $393 \mathrm{bp}$ ) were separated by electrophoresis in $8 \%$ polyacrylamide gels and viewed by silver staining. The genotypes were determined by viewing gel fragments; a fragment of $420 \mathrm{bp}$ indicated the genotype $4 \mathrm{~b} 4 \mathrm{~b}$, two fragments of 420 and $393 \mathrm{bp}$ indicated genotype $4 \mathrm{~b} 4 \mathrm{a}$, and a fragment of $393 \mathrm{bp}$ indicated genotype 4a4a.

\section{Estimation of haplotype frequencies and linkage disequilibrium}

The Estimating Haplotype (EH) software program (ftp:// linkage.rockefeller.edu/software/eh; accessed on November $19,2008)$ was used to estimate the haplotype frequencies (Terwillinger and Ott, 1994). We also used this software to perform a linkage analysis between each pairwise combination of alleles. This program calculates $\mathrm{D}^{\prime}$ (the maximumlikelihood estimate of disequilibrium), which is a standard measure of linkage disequilibrium. The $\mathrm{D}^{\prime}$ values for each pairwise combination of alleles were calculated as $\mathrm{D}^{\prime}=\mathrm{D} / \mathrm{D}_{\max }$, where $\mathrm{D}=\mathrm{h}-\mathrm{pq}$ (Cox et al., 1998). Here, $\mathrm{p}$ and $q$ are the frequencies for the rarer alleles of the two polymorphisms being tested for linkage, such that $\mathrm{p}<\mathrm{q} \leq 0.5$, and $\mathrm{h}$ is the frequency of the haplotype including the two specific alleles. When $\mathrm{D}<0, \mathrm{D}_{\max }=-\mathrm{pq}$; when $\mathrm{D}>0$, $\mathrm{D}_{\max }=\mathrm{p}(1-\mathrm{q})$. Thus, $\mathrm{D}^{\prime}$ values can vary from +1 to -1 , with a positive $\mathrm{D}^{\prime}$ indicating that the rarer alleles are associated and a negative $\mathrm{D}^{\prime}$ indicating that the rarer allele of one polymorphism is associated with the common allele at the other polymorphism.

\section{Statistical analysis}

The distribution of genotypes for each polymorphism was assessed for deviation from the Hardy-Weinberg equilibrium by using chi-squared tests (StatView for Windows, Cary, NC). Differences in the genotype frequency of each polymorphism and in the allele frequency between the ethnic groups were also assessed with chi-squared tests $(\alpha \leq 0.05)$.

\section{Results}

Table 1 shows the frequency of $e N O S$ genotypes and alleles in Amerindians compared to black and white Brazilians, as previously reported (Marroni et al., 2005). The distribution of genotypes for each polymorphism showed no deviation from Hardy-Weinberg equilibrium. There was remarkable disparity in the distribution of $e N O S$ genotypes and alleles among the three population groups (Table 1 and Fig. 1). The Asp298, $C^{-786}$, and 4a alleles were less common 
Table 1. Genotype and Allele Frequencies in the Amerindians of the Present Study Compared to Blacks and Whites, as Previously Reported

\begin{tabular}{|c|c|c|c|c|c|c|}
\hline & \multirow[b]{2}{*}{ Genotype } & \multicolumn{3}{|c|}{ Population groups } & \multirow[b]{2}{*}{$\chi^{2}$} & \multirow[b]{2}{*}{$\mathrm{p}$} \\
\hline & & $A m(\mathrm{n}=170)$ & $B(\mathrm{n}=136)$ & $W(\mathrm{n}=154)$ & & \\
\hline \multirow[t]{3}{*}{ Glu298Asp } & Glu, Glu & $0.900(153)$ & $0.713(97)^{*}$ & $0.422(65)^{*}$ & \multirow{3}{*}{54.46} & \multirow{3}{*}{$<0.0001$} \\
\hline & Glu, Asp & $0.100(17)$ & $0.272(37)^{*}$ & $0.500(77)^{*}$ & & \\
\hline & Asp, Asp & - & $0.015(2)^{*}$ & $0.078(12)^{*}$ & & \\
\hline \multirow[t]{3}{*}{$\mathrm{T}^{-786} \mathrm{C}$} & $\mathrm{T}, \mathrm{T}$ & 0.935 (159) & $0.640(87)^{*}$ & $0.311(48)^{*}$ & \multirow{3}{*}{87.10} & \multirow{3}{*}{$<0.0001$} \\
\hline & $\mathrm{T}, \mathrm{C}$ & 0.065 (11) & $0.330(45)^{*}$ & $0.539(83)^{*}$ & & \\
\hline & $\mathrm{C}, \mathrm{C}$ & - & $0.030(4)^{*}$ & $0.150(23)^{*}$ & & \\
\hline \multirow[t]{5}{*}{ Intron 4} & $4 b, 4 b$ & $0.923(157)$ & $0.470(64)^{*}$ & $0.701(108)^{*}$ & \multirow{4}{*}{52.35} & \multirow{4}{*}{$<0.0001$} \\
\hline & $4 b, 4 a$ & $0.071(12)$ & $0.390(53)^{*}$ & $0.273(42)^{*}$ & & \\
\hline & $4 a, 4 a$ & $0.006(1)$ & $0.125(17)^{*}$ & $0.026(4)^{*}$ & & \\
\hline & $4 b, 4 c$ & - & $0.015(2)^{*}$ & - & & \\
\hline & Alleles & $A m(\mathrm{n}=340)$ & $B(\mathrm{n}=272)$ & $W(\mathrm{n}=308)$ & & \\
\hline \multirow[t]{2}{*}{ Glu298Asp } & Glu & $0.950(323)$ & $0.849(231)^{*}$ & $0.672(207)^{*}$ & \multirow{2}{*}{27.68} & \multirow{2}{*}{$<0.0001$} \\
\hline & Asp & $0.050(17)$ & $0.151(41)^{*}$ & $0.328(101)^{*}$ & & \\
\hline \multirow[t]{2}{*}{$\mathrm{T}^{-786} \mathrm{C}$} & $\mathrm{T}$ & 0.968 (329) & $0.805(219)^{*}$ & $0.581(179)^{*}$ & \multirow[b]{2}{*}{45.05} & \multirow[b]{2}{*}{$<0.0001$} \\
\hline & $\mathrm{C}$ & 0.032 (11) & $0.195(53)^{*}$ & $0.419(129)^{*}$ & & \\
\hline \multirow{3}{*}{ Intron 4} & $4 \mathrm{~b}$ & 0.959 (326) & $0.673(183)^{*}$ & $0.821(253)^{*}$ & \multirow{3}{*}{26.97} & \multirow{3}{*}{$<0.0001$} \\
\hline & $4 a$ & $0.041(14)$ & $0.320(87)^{*}$ & $0.179(55)^{*}$ & & \\
\hline & $4 c$ & - & $0.007(2)^{*}$ & - & & \\
\hline
\end{tabular}

The data on blacks and whites were previously reported by Marroni et al. (2005). The rare allele 4c was grouped with the 4a allele before statistical analysis of intron 4 polymorphism.

${ }^{*} p<0.01$ compared to Amerindians (chi-squared tests).

Am, Amerindians; B, black Brazilians; W, white Brazilians.

in Amerindians (5.0\%, 3.2\%, and 4.1\%, respectively) than in blacks $(15.0 \%, 19.5 \%$, and $32.0 \%$, respectively) and whites (32.8\%, 41.9\%, and $17.9 \%$, respectively) $(p<0.001)$. Correspondingly, no homozygote Asp298 genotypes for exon 7, no homozygote $\mathrm{C}^{-786}$ genotypes for promoter region, and only one homozygote 4a genotype for intron 4 were found in Amerindians. Moreover, the heterozygote genotypes for the three polymorphisms were much less frequent in Amerindians than in blacks and whites $(p<0.001$ for all comparisons). We found significant differences in the distribution of intron 4 genotypes $(p<0.05$; Table 2$)$ among the three Amerindian tribes. However, no differences between these tribes were found when the other eNOS polymorphisms were considered.

The estimated haplotype frequencies of the three population groups are shown in Figure 2. We found significant differences in eNOS haplotype distribution when Amerin- dians were compared with blacks and whites $(p<0.01)$. The most common haplotype (H1) for the three groups combines the most common alleles for the three polymorphisms: Glu298, $\mathrm{T}^{-786}$, and $4 \mathrm{~b}$. For Amerindians, the second most common haplotype (H3, estimated frequency 4\%) includes the Asp298 allele in exon 7 , and the $\mathrm{T}^{-786}$ and $4 \mathrm{~b}$ alleles for the other two polymorphisms. The linkage analysis between each pairwise combination showed no specific associations between alleles for Amerindians.

\section{Discussion}

In the present study, we reported for the first time marked differences in the distribution of eNOS alleles in Amerindians compared with white and black subjects from Brazil (Table 1). We also found significant differences in estimated haplotype frequencies (Fig. 2) and in the association between
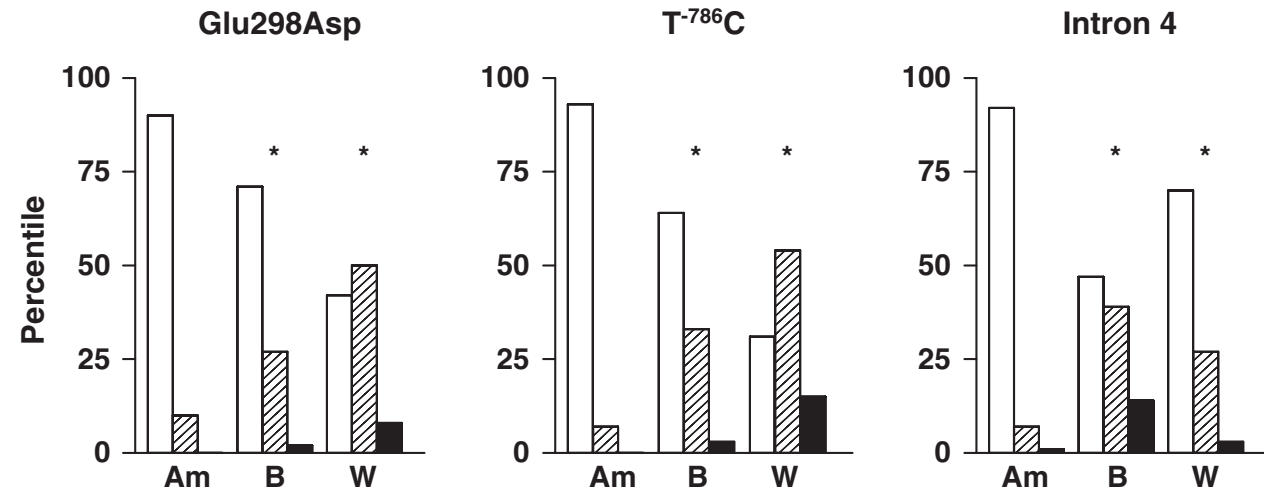

FIG. 1. Percentile distribution of genotypes in Amerindians compared to black and white Brazilians, as previously reported (Marroni et al., 2005). White bars, most common alleles homozygotes; hatched bars, heterozygotes; black bars, less common alleles homozygotes. ${ }^{*} p<0.01$ compared to Amerindians (chi-squared tests). 
Table 2. Allele Frequencies of the Endothelial Nitric Oxide Synthase Polymorphisms in the Three Amerindian Tribes from Brazilian Amazon

\begin{tabular}{|c|c|c|c|c|c|c|}
\hline \multirow[b]{2}{*}{ Tribes } & \multicolumn{2}{|c|}{ Glu298Asp } & \multicolumn{2}{|c|}{$T^{-786} \mathrm{C}$} & \multicolumn{2}{|c|}{ Intron 4} \\
\hline & Glu & $A s p$ & $T$ & C & $4 b$ & $4 a$ \\
\hline Tikúna $(n=228)$ & $0.965(220)$ & $0.035(8)$ & $0.974(222)$ & $0.026(6)$ & $0.956(218)$ & $0.044(10)$ \\
\hline Baníwa $(n=52)$ & $0.904(47)$ & $0.096(5)$ & $0.962(50)$ & $0.038(2)$ & $1.000(52)$ & $0.000(0)$ \\
\hline Kanamarí $(n=60)$ & $0.933(56)$ & $0.067(4)$ & $0.950(57)$ & $0.050(3)$ & $0.933(56)$ & $0.067(4)$ \\
\hline$\chi^{2}, p$ & $2.765,0.251$ & & $0.521,0.771$ & & $6.983,0.030$ & \\
\hline
\end{tabular}

alleles among these populations. The only difference observed in the distribution of intron 4 genotypes $(p<0.05$; Table 2) among the three Amerindian tribes could be explained by genetic drift effects and/or by the small sample size of the Baníwa tribe $(n=26)$.

Marked differences have been previously reported in the distribution of eNOS alleles and genotypes between black and white Brazilians (Marroni et al., 2005). Here, we expanded these data and compared these two groups with Amerindians from the Brazilian Amazon, and found striking differences among the three groups. Confirming these dissimilarities, the Amerindians showed no association (linkage) between the less common alleles, as previously reported in whites and blacks (Marroni et al., 2005). The most common haplotype was found at a higher estimated frequency in Amerindians (89\%) than in blacks (45\%) and whites (41\%). Moreover, the Amerindians exhibited a notable lower haplotypic diversity compared to blacks and whites. The eNOS genotypes and haplotype distribution we found are consistent with the idea that Amerindians have less genetic diversity than other population groups, as detailed elsewhere (Wang et al., 2007). These findings may help to understand how the combination of polymorphisms and distinct haplotypes influence the interethnic disparities in NO bioavailability, cardiovascular risk (Stein et al., 1997; Sareli et al., 2001; Kalinowski et al., 2004; Li et al., 2004), and response to drugs (Nagassaki et al., 2006, 2008; Souza-Costa et al., 2007).

There is only one previous study reporting the frequencies of eNOS polymorphisms in the Mexican Amerindians Huastec, Mayan, and Mayo (Rosas-Vargas et al., 2003), which showed that the Asp298 allele frequency in the Huastec $(11.5 \%)$ is significantly higher $(p<0.01)$ than the $5.0 \%$ fre- quency we found in the Amerindians studied here. This difference between Brazilian and Mexican Amerindians could be attributed to European admixture in the Huastec group (Rosas-Vargas et al., 2003). However, despite the scarcity of data, these findings suggest similar allele frequencies for North and South Amerindians. More studies are required to confirm these findings.

We have also compared our results with those from the HapMap project (HapMap, 2003). Significant differences were found when the distribution of genotype and allele frequencies in Amerindians were compared with that found in the HapMap project CEU population for the promoter region and exon 7 polymorphisms $(p<0.01)$. However, differences between Amerindians and CHB and YRI HapMap populations were observed only for exon 7 and promoter region polymorphisms, respectively $(p<0.05)$.

Previous studies have attempted to demonstrate the functionality of the eNOS polymorphisms studied here. For example, while the $\mathrm{C}^{-786}$ allele reduces the eNOS promoter activity by approximately 50\% (Nakayama et al., 1999; Miyamoto et al., 2000), the polymorphism in exon 7 may affect eNOS localization to caveolar membrane (Joshi et al., 2007). The intron 4 VNTR, however, modifies the levels of a 27-nt small RNA, which decreases the eNOS mRNA and protein levels (Zhang et al., 2005). It would be very interesting to figure out how different combinations of these eNOS polymorphisms (haplotypes) affect eNOS function and the incidence of clinical events. Many recent studies have implicated eNOS polymorphisms in the development of cardiovascular diseases (Casas et al., 2006; Cooke et al., 2007), and it is possible that interethnic differences in NO-mediated effects may result from a disproportionate distribution of eNOS alleles among

FIG. 2. Estimated haplotype frequencies in the Amerindians of the present study (black bars) compared to black (hatched bars) and white (white bars) Brazilians, as previously reported (Marroni et al., 2005). The numbers above the bars indicate the estimated number of haplotypes corresponding to each bar. The total number of haplotypes is the total number of subjects multiplied by 2 because each subject has two haplotypes. Haplotypes are defined as H1, T Glu b; H2, T Glu a; H3, T Asp b; H4, T Asp a; H5, C Glu b; H6, C Glu a; H7, C Asp b; H8, C Asp a. ${ }^{*} p<0.01$ compared to Amerindians.

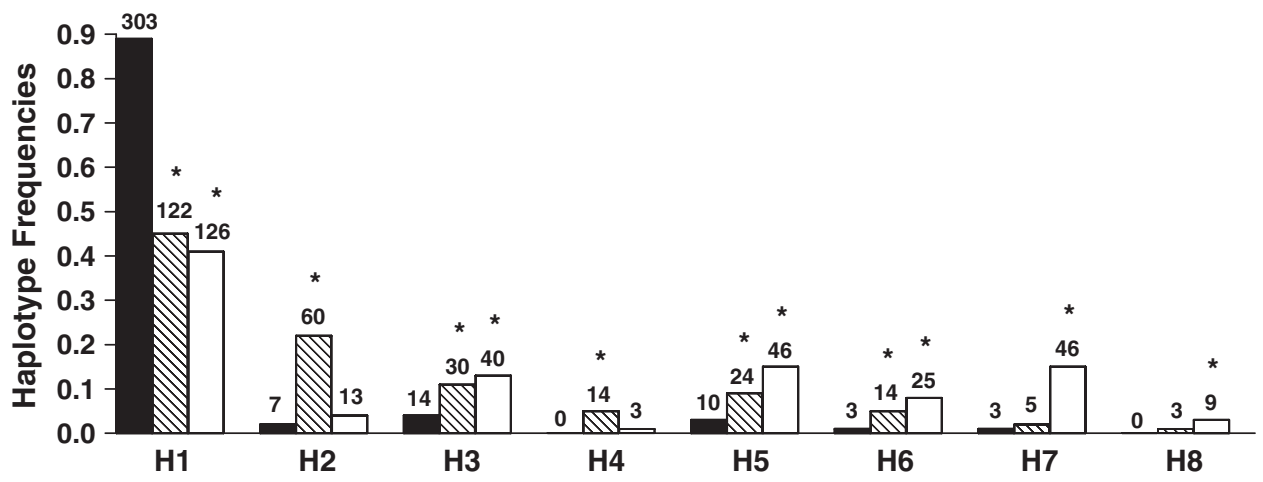


different population groups (Stein et al., 2001; Tanus-Santos et al., 2001; Marroni et al., 2005). Of note, the three Amerindian tribes studied are characterized by low admixture levels (estimated as $2-3 \%$ ) with nonindigenous people (Luizon et al., 2008). They had remarkably lower prevalence of the alleles 298Asp and $C^{-786}$ than the other groups. These findings could explain, at least in part, why isolated Amerindian tribes have lower incidence of cardiovascular diseases, as shown in the Amondava population of Brazilian Amazon (Pavan et al., 1999). In addition to a possible genetic predisposition not analyzed in the Amondava, a traditional lifestyle (no contact with civilization, diet based on complex carbohydrates and vegetables, high energy expenditure) may protect against the development of hypertension, hypercholesterolemia, and diabetes (Pavan et al., 1999).

In addition to modifying disease susceptibility, eNOS polymorphisms may affect drug responses (Nagassaki et al., 2006, 2008; Souza-Costa et al., 2007). For example, atorvastatin produced significant improvements in $\mathrm{NO}$ availability (Nagassaki et al., 2006) and anti-inflammatory effects (SouzaCosta et al., 2007) in CC genotype (but not TT genotype) subjects genotyped for the $\mathrm{T}^{-786} \mathrm{C}$ polymorphism. Because we found no subjects with CC genotype among the 170 Amerindians studied here, we could speculate that atorvastatin may produce less intense effects in Amerindians compared with whites. However, this hypothesis remains to be proved.

In conclusion, we found striking differences in the distribution of clinically relevant eNOS alleles and haplotypes among Amerindian, black, and white Brazilians. These findings are consistent with a lower genetic diversity in Amerindians compared with blacks and whites and may be of major relevance for case-control association studies focusing on eNOS gene polymorphisms in admixed populations, such as the American and the Brazilian populations. Our findings may in part explain the interpopulation disparities in cardiovascular risk and response to drugs.

\section{Acknowledgments}

This study was supported by Fundação de Amparo à Pesquisa do Estado de Sao Paulo, Conselho Nacional de Desenvolvimento Científico e Tecnologico, and Coordenadoria de Aperfeiçoamento de Pessoal de Nível Superior.

\section{Disclosure Statement}

No competing financial interests exist.

\section{References}

Cardon, L.R., and Bell, J.I. (2001). Association study designs for complex diseases. Nat Rev Genet 2, 91-99.

Casas, J.P., Cavalleri, G.L., Bautista, L.E., Smeeth, L., Humphries, S.E., and Hingorani, A.D. (2006). Endothelial nitric oxide synthase gene polymorphisms and cardiovascular disease: a HuGE review. Am J Epidemiol 164, 921-935.

Cooke, G.E., Doshi, A., and Binkley, P.F. (2007). Endothelial nitric oxide synthase gene: prospects for treatment of heart disease. Pharmacogenomics 8, 1723-1734.

Cox, A., Camp, N.J., Nicklin, M.J., di Giovine, F.S., and Duff, G.W. (1998). An analysis of linkage disequilibrium in the interleukin-1 gene cluster, using a novel grouping method for multiallelic markers. Am J Hum Genet 62, 1180-1188.
Ferreira, L.B., Mendes-Junior, C.T., Wiezel, C.E., Luizon, M.R., and Simoes, A.L. (2006). Genomic ancestry of a sample population from the state of Sao Paulo, Brazil. Am J Hum Biol 18, 702-705.

HapMap. (2003). The international HapMap project. Nature 426, 789-796.

Hingorani, A.D. (2001). Polymorphisms in endothelial nitric oxide synthase and atherogenesis: John French Lecture 2000. Atherosclerosis 154, 521-527.

Joshi, M.S., Mineo, C., Shaul, P.W., and Bauer, J.A. (2007). Biochemical consequences of the NOS3 Glu298Asp variation in human endothelium: altered caveolar localization and impaired response to shear. Faseb J 21, 2655-2663.

Kalinowski, L., Dobrucki, I.T., and Malinski, T. (2004). Racespecific differences in endothelial function: predisposition of African Americans to vascular diseases. Circulation 109, 25112517.

Li, R., Lyn, D., Lapu-Bula, R., Oduwole, A., Igho-Pemu, P., Lankford, B., Morgan, J., Nkemdechi, S., Liu, G., Pack, C., Silvestrov, N., von Deutsch, D.A., Song, Q., Abukhalaf, I.K., and Ofili, E. (2004). Relation of endothelial nitric oxide synthase gene to plasma nitric oxide level, endothelial function, and blood pressure in African Americans. Am J Hypertens 17, 560-567.

Luizon, M.R., Mendes-Junior, C.T., De Oliveira, S.F., and Simoes, A.L. (2008). Ancestry informative markers in Amerindians from Brazilian Amazon. Am J Hum Biol 20, 86-90.

Marroni, A.S., Metzger, I.F., Souza-Costa, D.C., Nagassaki, S., Sandrim, V.C., Correa, R.X., Rios-Santos, F., and Tanus-Santos, J.E. (2005). Consistent interethnic differences in the distribution of clinically relevant endothelial nitric oxide synthase genetic polymorphisms. Nitric Oxide 12, 177-182.

Mestriner, M.A., Simoes, A.L., and Salzano, F.M. (1980). New studies on the esterase D polymorphism in South American Indians. Am J Phys Anthropol 52, 95-101.

Metzger, I.F., Sertorio, J.T., and Tanus-Santos, J.E. (2007). Modulation of nitric oxide formation by endothelial nitric oxide synthase gene haplotypes. Free Radic Biol Med 43, 987-992.

Metzger, I.F., Souza-Costa, D.C., Marroni, A.S., Nagassaki, S., Desta, Z., Flockhart, D.A., and Tanus-Santos, J.E. (2005). Endothelial nitric oxide synthase gene haplotypes associated with circulating concentrations of nitric oxide products in healthy men. Pharmacogenet Genomics 15, 565-570.

Miyamoto, Y., Saito, Y., Nakayama, M., Shimasaki, Y., Yoshimura, T., Yoshimura, M., Harada, M., Kajiyama, N., Kishimoto, I., Kuwahara, K., Hino, J., Ogawa, E., Hamanaka, I., Kamitani, S., Takahashi, N., Kawakami, R., Kangawa, K., Yasue, H., and Nakao, K. (2000). Replication protein A1 reduces transcription of the endothelial nitric oxide synthase gene containing a $-786 \mathrm{~T} \rightarrow \mathrm{C}$ mutation associated with coronary spastic angina. Hum Mol Genet 9, 2629-2637.

Nagassaki, S., Herculano, R.D., Graeff, C.F., and Tanus-Santos, J.E. (2009). eNOS T-786C polymorphism affects atorvastatininduced changes in erythrocyte membrane fluidity. Eur J Clin Pharmacol. Eur J Clin Pharmacol 65, 385-392.

Nagassaki, S., Sertorio, J.T., Metzger, I.F., Bem, A.F., Rocha, J.B., and Tanus-Santos, J.E. (2006). eNOS gene T-786C polymorphism modulates atorvastatin-induced increase in blood nitrite. Free Radic Biol Med 41, 1044-1049.

Nakayama, M., Yasue, H., Yoshimura, M., Shimasaki, Y., Kugiyama, K., Ogawa, H., Motoyama, T., Saito, Y., Ogawa, Y., Miyamoto, Y., and Nakao, K. (1999). T-786 $\rightarrow$ C mutation in the 5 '-flanking region of the endothelial nitric oxide synthase gene is associated with coronary spasm. Circulation 99, 2864-2870. 
Neel, J.V., Gershowitz, H., Mohrenweiser, H.W., Amos, B., Kostyu, D.D., Salzano, F.M., Mestriner, M.A., Lawrence, D., Simoes, A.L., Smouse, P.E., Oliver, W.J., Spielman, R.S., and Neel, J.V., Jr. (1980). Genetic studies on the Ticuna, an enigmatic tribe of central Amazonas. Ann Hum Genet 44, 37-54.

Nejatizadeh, A., Kumar, R., Stobdan, T., Goyal, A.K., Sikdar, S., Gupta, M., Javed, S., and Pasha, M.A. (2008). Endothelial nitric oxide synthase gene haplotypes and circulating nitric oxide levels significantly associate with risk of essential hypertension. Free Radic Biol Med 44, 1912-1918.

Parra, F.C., Amado, R.C., Lambertucci, J.R., Rocha, J., Antunes, C.M., and Pena, S.D. (2003). Color and genomic ancestry in Brazilians. Proc Natl Acad Sci U S A 100, 177-182.

Pavan, L., Casiglia, E., Braga, L.M., Winnicki, M., Puato, M., Pauletto, P., and Pessina, A.C. (1999). Effects of a traditional lifestyle on the cardiovascular risk profile: the Amondava population of the Brazilian Amazon. Comparison with matched African, Italian and Polish populations. J Hypertens 17, 749-756.

Risch, N.J. (2000). Searching for genetic determinants in the new millennium. Nature 405, 847-856.

Rosas-Vargas, H., Flores-Segura, A., Guizada-Claure, B., VargasAlarcon, G., Granados, J., Salamanca, F., and Coral-Vazquez, R. (2003). Endothelial nitric oxide synthase gene polymorphism in the Indian and Mestizo populations of Mexico. Hum Biol 75, 91-96.

Sandrim, V.C., Coelho, E.B., Nobre, F., Arado, G.M., Lanchote, V.L., and Tanus-Santos, J.E. (2006a). Susceptible and protective eNOS haplotypes in hypertensive black and white subjects. Atherosclerosis 186, 428-432.

Sandrim, V.C., de Syllos, R.W., Lisboa, H.R., Tres, G.S., and Tanus-Santos, J.E. (2006b). Endothelial nitric oxide synthase haplotypes affect the susceptibility to hypertension in patients with type 2 diabetes mellitus. Atherosclerosis 189, 241-246.

Sandrim, V.C., de Syllos, R.W., Lisboa, H.R., Tres, G.S., and Tanus-Santos, J.E. (2007). Influence of eNOS haplotypes on the plasma nitric oxide products concentrations in hypertensive and type 2 diabetes mellitus patients. Nitric Oxide 16, 348-355.

Sandrim, V.C., Palei, A.C., Cavalli, R.C., Araujo, F.M., Ramos, E.S., Duarte, G., and Tanus-Santos, J.E. (2008a). eNOS haplotypes associated with gestational hypertension or preeclampsia. Pharmacogenomics 9, 1467-1473.

Sandrim, V.C., Palei, A.C., Metzger, I.F., Gomes, V.A., Cavalli, R.C., and Tanus-Santos, J.E. (2008b). Nitric oxide formation is inversely related to serum levels of antiangiogenic factors soluble fms-like tyrosine kinase- 1 and soluble endogline in preeclampsia. Hypertension 52, 402-407.

Sareli, P., Radevski, I.V., Valtchanova, Z.P., Libhaber, E., Candy, G.P., Den Hond, E., Libhaber, C., Skudicky, D., Wang, J.G., and Staessen, J.A. (2001). Efficacy of different drug classes used to initiate antihypertensive treatment in black subjects: results of a randomized trial in Johannesburg, South Africa. Arch Intern Med 161, 965-971.
Souza-Costa, D.C., Sandrim, V.C., Lopes, L.F., Gerlach, R.F., Rego, E.M., and Tanus-Santos, J.E. (2007). Anti-inflammatory effects of atorvastatin: modulation by the T-786C polymorphism in the endothelial nitric oxide synthase gene. Atherosclerosis 193, 438-444.

Stein, C.M., Lang, C.C., Nelson, R., Brown, M., and Wood, A.J. (1997). Vasodilation in black Americans: attenuated nitric oxide-mediated responses. Clin Pharmacol Ther 62, 436-443.

Stein, C.M., Lang, C.C., Xie, H.G., and Wood, A.J. (2001). Hypertension in black people: study of specific genotypes and phenotypes will provide a greater understanding of interindividual and interethnic variability in blood pressure regulation than studies based on race. Pharmacogenetics 11, 95-110.

Tanus-Santos, J.E., Desai, M., Deak, L.R., Pezzullo, J.C., Abernethy, D.R., Flockhart, D.A., and Freedman, J.E. (2002). Effects of endothelial nitric oxide synthase gene polymorphisms on platelet function, nitric oxide release, and interactions with estradiol. Pharmacogenetics 12, 407-413.

Tanus-Santos, J.E., Desai, M., and Flockhart, D.A. (2001). Effects of ethnicity on the distribution of clinically relevant endothelial nitric oxide variants. Pharmacogenetics 11, 719-725.

Terwillinger, J.D., and Ott, J. (1994). Handbook of Linkage Analysis (The Johns Hopkins University Press, New York).

Wang, S., Lewis, C.M., Jakobsson, M., Ramachandran, S., Ray, N., Bedoya, G., Rojas, W., Parra, M.V., Molina, J.A., Gallo, C., Mazzotti, G., Poletti, G., Hill, K., Hurtado, A.M., Labuda, D., Klitz, W., Barrantes, R., Bortolini, M.C., Salzano, F.M., PetzlErler, M.L., Tsuneto, L.T., Llop, E., Rothhammer, F., Excoffier, L., Feldman, M.W., Rosenberg, N.A., and Ruiz-Linares, A. (2007). Genetic variation and population structure in native Americans. PLoS Genet 3, 2049-2067.

Yetik-Anacak, G., and Catravas, J.D. (2006). Nitric oxide and the endothelium: history and impact on cardiovascular disease. Vascul Pharmacol 45, 268-276.

Zhang, M.X., Ou, H., Shen, Y.H., Wang, J., Wang, J., Coselli, J., and Wang, X.L. (2005). Regulation of endothelial nitric oxide synthase by small RNA. Proc Natl Acad Sci U S A 102, 16967-16972.

Address correspondence to: Jose Eduardo Tanus-Santos, M.D., Ph.D. Department of Pharmacology Faculty of Medicine of Ribeirao Preto University of Sao Paulo Ave. Bandeirantes, 3900 14049-900 Ribeirao Preto Sao Paulo Brazil

E-mail: tanus@fmrp.usp.br

Received for publication February 25, 2009; received in revised form March 13, 2009; accepted March 16, 2009. 